\title{
Swiss Rainfall Mass Curves and their Influence on Extreme Flood Simulation
}

\section{Fränz Zeimetz, Bettina Schaefli, Guillaume Artigue, Javier García Hernández \& Anton J. Schleiss}

\section{Water Resources Management}

An International Journal - Published for the European Water Resources Association (EWRA)

\section{ISSN 0920-4741}

Volume 32

Number 8

Water Resour Manage (2018)

32:2625-2638

DOI 10.1007/s11269-018-1948-y

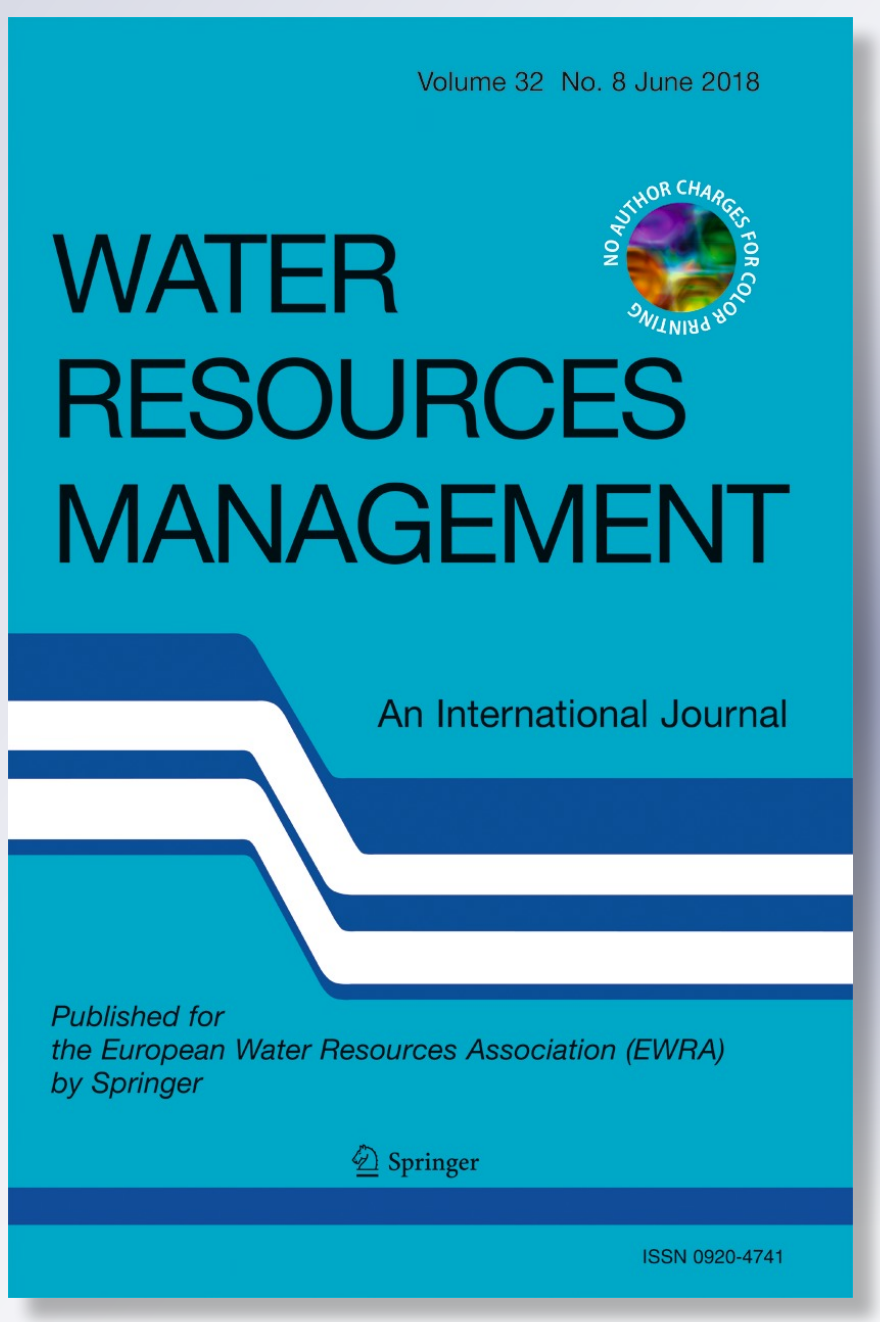

Springer 
Your article is protected by copyright and all rights are held exclusively by Springer Science+Business Media B.V., part of Springer Nature. This e-offprint is for personal use only and shall not be self-archived in electronic repositories. If you wish to self-archive your article, please use the accepted manuscript version for posting on your own website. You may further deposit the accepted manuscript version in any repository, provided it is only made publicly available 12 months after official publication or later and provided acknowledgement is given to the original source of publication and a link is inserted to the published article on Springer's website. The link must be accompanied by the following text: "The final publication is available at link.springer.com". 


\title{
Swiss Rainfall Mass Curves and their Influence on Extreme Flood Simulation
}

\author{
Fränz Zeimetz ${ }^{1}$ (D) Bettina Schaefli ${ }^{2}$ - Guillaume Artigue ${ }^{1}$ • \\ Javier García Hernández ${ }^{3}$ • Anton J. Schleiss ${ }^{1}$
}

Received: 18 May 2017 / Accepted: 23 February 2018 /

Published online: 7 March 2018

(C) Springer Science+Business Media B.V., part of Springer Nature 2018

\begin{abstract}
Extreme flood estimates for dam safety are routinely obtained from hydrologic simulations driven by selected design storms. The temporal structure of such design storms can be obtained from Rainfall Mass Curves (RMCs), which are adimensionalized curves of the cumulative precipitation depth as a function of event duration. This paper assesses for the first time the spatialand temporal variability of observed RMCs for Switzerland, an Alpine region with complex topography. The relevance of the detected RMC variability for extreme flood estimation is illustrated based on an application to a high elevation catchment, the Mattmark dam catchment in the Swiss Alps. The obtained results underline that quantile RCMs represent a simple yet powerful tool to construct design storms for dam safety verification and that regional, seasonal and event-duration effects on RMCs are small enough to justify the use of a unique set of Swiss-wide quantile RMCs. The presented analysis could be refined in the future by explicitly accounting for orographic, convective or frontal precipitation events.
\end{abstract}

Keywords Rainfall mass curve $\cdot$ Huffcurves $\cdot$ extreme floods $\cdot$ Probable Maximum Precipitation $\cdot$ Hydrologic simulation $\cdot$ Design storm $\cdot$ Rainfall-runoff model

Electronic supplementary material The online version of this article (https://doi.org/10.1007/s11269-0181948-y) contains supplementary material, which is available to authorized users.

Fränz Zeimetz

franz.zeimetz@epfl.ch

1 Ecole Polytechnique Fédérale de Lausanne (EPFL), Lausanne, Switzerland

2 Faculty of Geosciences and Environment, Universite de Lausanne (UNIL), Institute of Earth Surface Dynamics, Lausanne, Switzerland

3 Centre de recherche sur l'environnement alpin (CREALP), Sion, Switzerland 


\section{Introduction}

Rainfall mass curves (RMCs) are adimensionalized curves that represent the cumulative percentage of precipitated water against the adimensionalized duration of a precipitation event. They are used to attribute a temporal structure to design rainfall depths in order to generate a hyetograph (Bérod et al. 1992; Veneziano and Villani 1999; Prodanovic and Simonovic 2004). RMCs have been introduced 50 years ago and are used in particular in the context of extreme event estimation (Tsihrintzis and Sidan 1998; Golian et al. 2010; Caballero and Rahman 2013; Vernieuwe et al. 2015; Ghassabi et al. 2016)

The first comprehensive analysis of RMCs is due to Huff (1967), who analyzed 30-min precipitation data from 49 gauges spread over $1037 \mathrm{~km}^{2}$ in the State of Illinois (as reported in Azli and Rao 2010). These curves remain an important reference today (Dolsak et al. 2016; Pan et al. 2017). He distinguished between four different types of curves by separating them into 4 groups (so-called quartiles) depending on the moment of precipitation burst occurrence: If the precipitation burst occurs in the first $25 \%$ of the total precipitation duration, it belongs to he the first quartile. The second quartile is characterized by a precipitation burst occurring between $25 \%$ and $50 \%$ of the total duration. The third and fourth quartiles are defined by bursts occurring between $50 \%$ and $75 \%$ and after $75 \%$ of the total duration respectively. Huff (1967) found that short events (less than $6 \mathrm{~h}$ ) were mostly associated with the first quartile, storms with a duration between 6 and $24 \mathrm{~h}$ with the second quartile, events with a duration between 12 and $24 \mathrm{~h}$ with the third quartile and events lasting longer than $24 \mathrm{~h}$ with the fourth quantile. Later on, several studies showed that in the US, RMCs do not necessarily depend on the rainfall duration (Guo and Hargadin 2009; Bonta 2004; National Environment Research Council 1975). Bonta (2004) in particular questioned the use of an arbitrary number of percentiles for RMC classification; he hypothesized that the dependence between event duration and precipitation burst timing was an artefact resulting from the lack of a seasonal analysis in the work of Huff (1967).

Bonta (2004) furthermore hypothesized that a seasonal analysis would show that the storm durations within a season tend to be similar and that the Huff curves are independent from storm quartiles. These suppositions of Bonta (2004) were partially confirmed by Back (2011) for Brazil. This study concluded that first and second quartile storms are more likely to occur in summer, whereas third and fourth quartile storms are evenly distributed throughout the entire year.

Several studies analyzed the regional variability of RMCs (Shaw et al. 1984; Kimoto et al. 2011) and proposed methods to determine regional RMCs (National Environment Research Council 1975; Azli and Rao 2010). Such analyses are necessarily strongly climate specific and not directly transferable to other regions. A potential solution to overcome this case study specificity is the use of so-called design Huff curves (Natural Resources Conservation Service 1986), which are synthetic temporal rainfall structures for the construction of design storms. However, these curves have been shown to lead to unrealistic results (Kimoto et al. 2011; Guo and Hargadin 2009; Ghassabi et al. 2016), similar to the Chicago method (Keifer and Chu 1957), which has been shown to give too intense burst peaks compared to observed storm peaks (Alfieri et al. 2008; Watt and Marsalek 2013).

This study gives the first comprehensive analysis of RMCs for a region with a complex Alpine topography. Based on the case of Switzerland, the regional and seasonal variability of RMCs is assessed in detail and compared to the variability related to event duration. A key question is hereby whether the observed ensemble of RMCs can be collapsed into a single 
reference RMC representative for the entire area. The relevance of the identified spatial and temporal variabilities of RMC shapes is assessed through an application to flood estimation for a selected case study.

\section{Data}

\subsection{Rain Gauge Data}

Hourly precipitation data was provided by MeteoSwiss at 99 locations (Fig. 1) spread over Switzerland $\left(41,285 \mathrm{~km}^{2}\right)$. The hourly precipitation measurements started in 1981 but not all 99 stations have been operational since 1981 and some stations have been removed since then. A total of 52 stations have a record of over 30 years, 5 stations started recording after 2013.

Despite of the different record lengths, all the available data from all stations was considered for this study. This is justified by the fact that for RMC analysis, all data are aggregated to six large regions (Fig. 1), which leads to large data sets for each region. This data aggregation smoothes out the differences in record lengths per rain gauge.

For the purpose of this study, storm events were identified as events that are separated by at least $3 \mathrm{~h}$ of precipitation with intensity equal or smaller than $0.1 \mathrm{~mm} / \mathrm{h}$ (corresponding to the detection limit of the rain gauges). An example of RMCs obtained from this data is given in Fig. 2 that illustrates three hyetographs with their respective RMC, one for early, centered and late burst precipitation events.

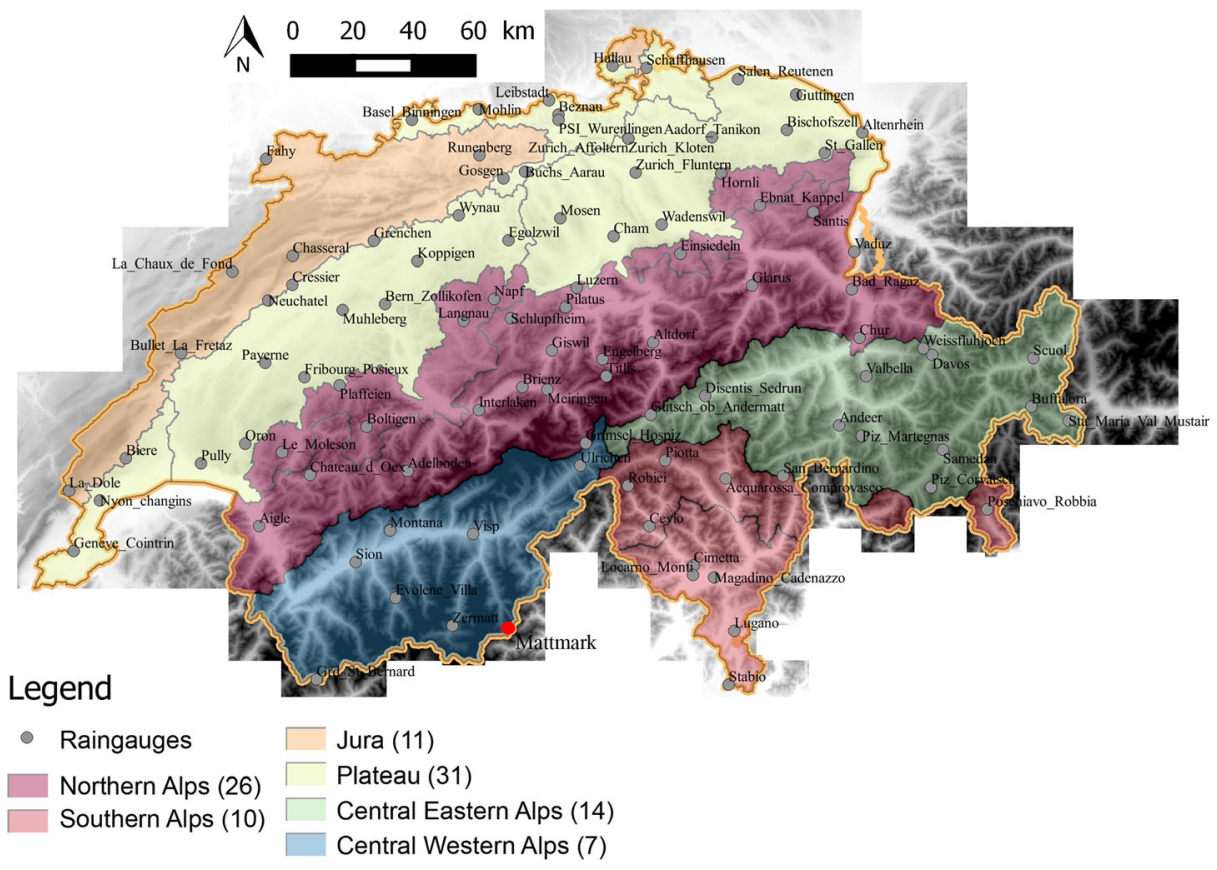

Fig. 1 Location of the rain gauges within the six Swiss regions (number of gauges per region given in parentheses). Shown is also the location of the case study catchment Mattmark 


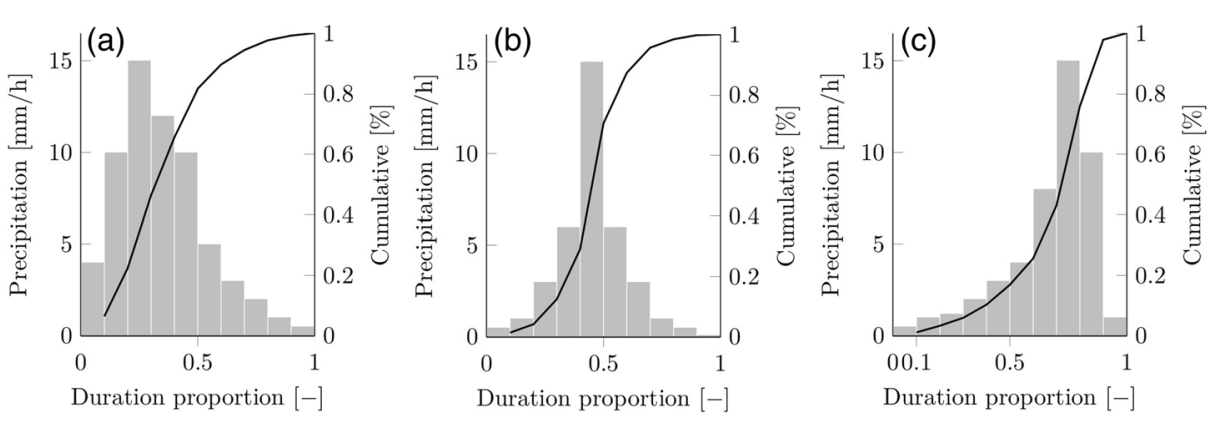

Fig. 2 Schemas of synthetic RMCs represented with the related hyetographs; a) early bursting event, b) centered event, c) late bursting event

\subsection{Data for Flood Estimation}

For flood estimation, design rainfall volumes were obtained from so-called Probable Maximum Precipitation (PMP) maps (eg. Chen et al. 2017) for Switzerland (Hertig et al. 2005; Hertig and Fallot 2009) for durations of 4 h, 8 h, 12 h, 24 h and 35 h. These maps are valid only for spring to autumn (high air temperatures are necessary to sustain a PMP event) (Hertig and Fallot 2009). Following World Meteorological Organisation (2009), it can be assumed that such PMP maps represent the spatial distribution of a stationary event, which allows a separate analysis of the spatial and temporal variability of the event. Accordingly, RMCs can be used under this stationarity assumption to assign a temporal structure to the PMP maps.

\section{Methods}

\subsection{Construction of Quantile RMCs}

Rather than analyzing the shape of the RMC of individual rainfall events, it is common to analyze what is called here quantile RMCs (Azli and Rao 2010; Bonta 2004; Bonta and Shahalam 2003; Shaw et al. 1984; Huff 1967). Such curves are constructed by pooling together the RMC of all considered precipitation events (either from a single rain gauge or from a set of rain gauges) and by calculating a given quantile (e.g. 5\%) for each individual point on the abscissa in the RMC plot (an example is shown in Fig. 3). For the present study, the $5 \%, 50 \%$ and $95 \%$ quantile curves were analyzed.

Figure 2 illustrates the relation between the RMC shape and the timing of the precipitation burst. It can be concluded that RMC shapes corresponding to small quantiles lead to a late bursting storm, median-like RMC shapes to a storm with a more or less centered burst and larger quantile RMCs to an early bursting storm.

\subsection{Analysis of Spatial and Temporal RMC Vvariability}

The following four seasons were defined for the analysis of seasonal RMC variability: (1) winter (December to February), (2) spring (March to May), (3) summer (June to August) and (4) autumn (September to November). If nothing else is specified, the analyzed precipitation event durations are $4 \mathrm{~h}, 12 \mathrm{~h}, 24 \mathrm{~h}$ and $35 \mathrm{~h}$. 


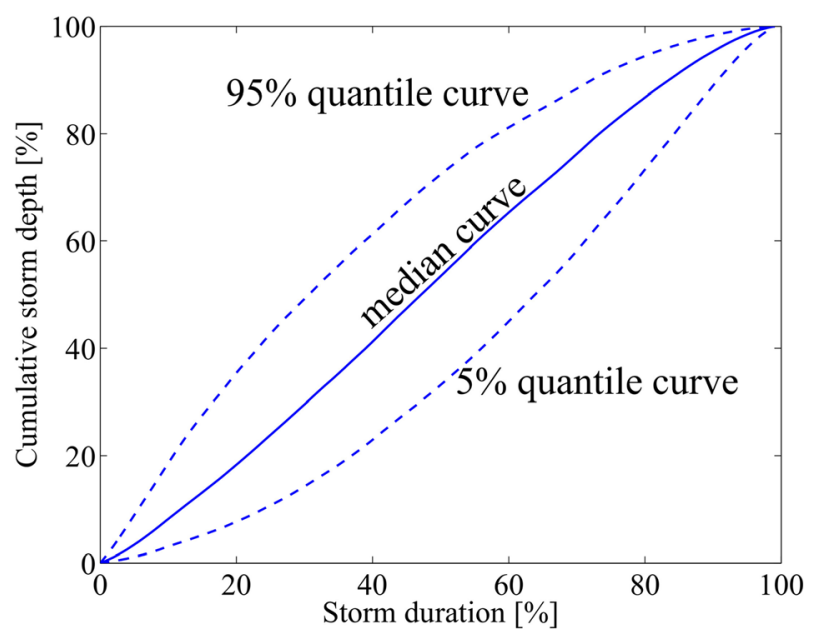

Fig. 3 Reference quantile RMCs for Switzerland (independent of region, season or event duration). The underlying data points are given in the Supplementary Material

Topography can be supposed to have an important impact on the RMCs (Kimoto et al. 2011), in particular through its influence on the precipitation event type. Accordingly, given the complex topography of Switzerland, the quantile RMCs can be expected to show strong regional variability. For the analysis in this paper, the six biogeographical zones of Switzerland (Swiss Federal Office for the Environment 2001) were retained. These regions correspond to the three main topographical regions, the Jura mountains, the low-lying area (so-called Plateau area) and the Alps, which are further subdivided into four climatic zones (Fig. 1).

To complete the analysis of quantile RMC variability, a reference curve was constructed for each of the considered quantiles. These reference curves were derived by pooling the events from all 99 rain gauges without any distinction of location, season or event duration (see Fig. 3).

\subsection{Assessment of RMC Variability Effects on Flood Estimation}

The relevance of RMC variability for flood estimation is assessed based on a hydrological application to the Mattmark dam catchment (Fig. 1), a $36 \mathrm{~km}^{2}$ catchment going from $2174 \mathrm{~m}$ asl. to $3898 \mathrm{~m}$ asl., with a glacier cover of around $28 \%\left(10 \mathrm{~km}^{2}\right)$. Besides the influence on the generated hydrographs, the impact of RCM variability on the water level in the Mattmark dam reservoir was also assessed (see Fig. 3.14 of Zeimetz 2017, for the water level - water volume relationship).

The precipitation-runoff simulation was performed with the so-called Glacier Snow MeltSoil contribution model (GSM-Socont Schaefli et al. 2005; Schaefli and Zehe 2009; Jordan et al. 2012), a semi-distributed conceptual hydrological model developed for mountainous catchments. Given the small size of the study catchment, river routing was neglected. The model was duly calibrated and validated against observed data (for details see Zeimetz 2017; Zeimetz et al. in press). The hydrological model was initialized with the same values for all seasons (no snow, $30 \%$ of soil saturation) and with a 0_C isothermal altitude at $4500 \mathrm{~m}$ asl., which ensures absence of snowfall on the entire catchment (Zeimetz et al. 2017). This ensures that the results are independent of air temperature and initial catchment conditions. 
The effect of RMC variability on flood estimation was quantified by comparing the hydrographs derived from seasonal and duration-dependent RMCs to the hydrographs derived from the reference RMC (see Section 3.1). The three quantile RMCs (5\%, 50\% and 95\%) were considered separately.

\section{Results and Discussion}

\subsection{Regional Variability of Swiss RMCs}

The regional variability is discussed here in detail for summer (Fig. 4) and winter (Fig. 5), the two seasons that are marked by the strongest climatic differences (see also Figures S1 and S2 of the Supplementary Material for spring and autumn).

The regional variability is overall small but it is most pronounced for summer. In Fig. 4, it can be seen that for the $95 \%$ quantile, the Southern Alps tend to have an earlier burst than the other regions and that for the $5 \%$ quantile, most of the precipitation volume is released at the end of the event. These differences in the regional RMCs are probably related to climatic differences between the Southern Alps and the rest of Switzerland, with intense summer storms related to high moisture inflow and orographic effects (Pedrozzi 2004). The fact that regional variations are smaller for the

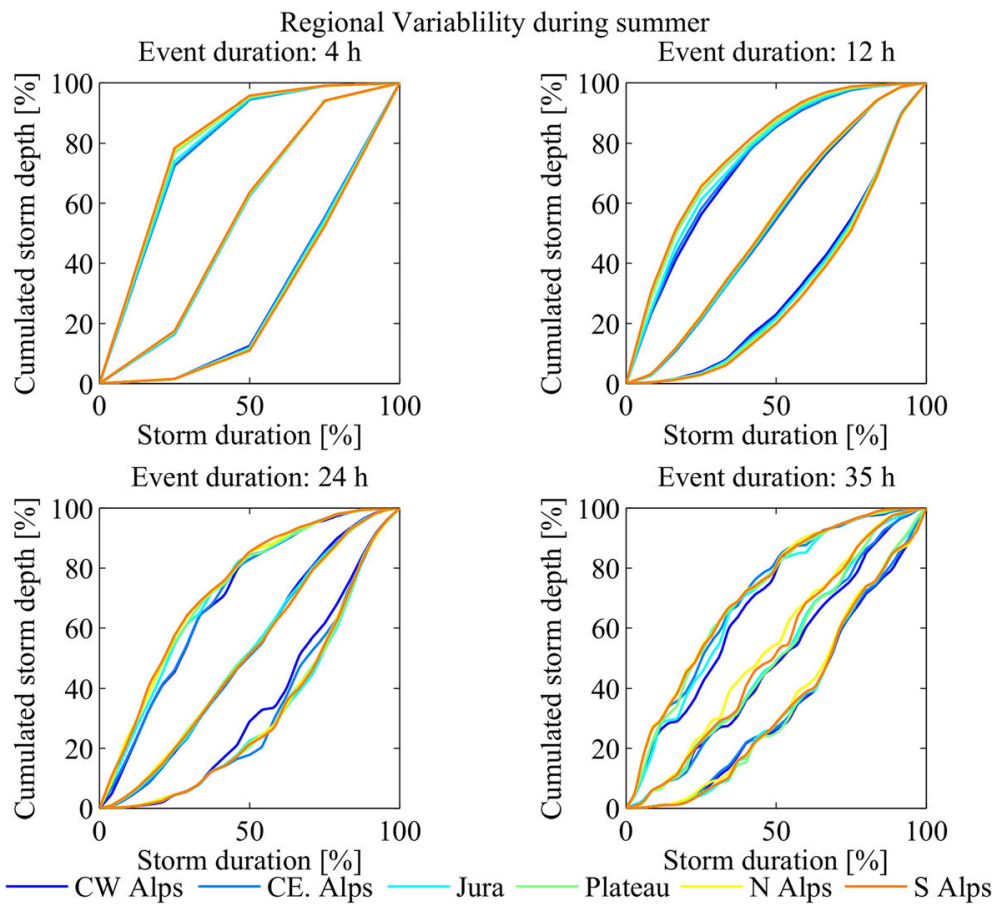

Fig. 4 Regional quantile RMCs for the summer season; abbreviations stand for: Central Western (CW), Central Eastern (CE), Northern (N) and Southern (S) Alps; the panels show the four event durations (4 h, 12 h, 24 h, 35 h) 
Regional Variablility during winter

Event duration: $4 \mathrm{~h}$

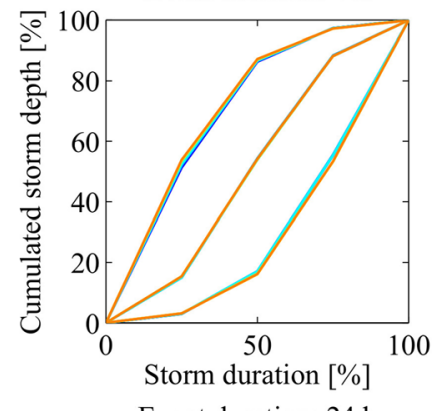

Event duration: $24 \mathrm{~h}$

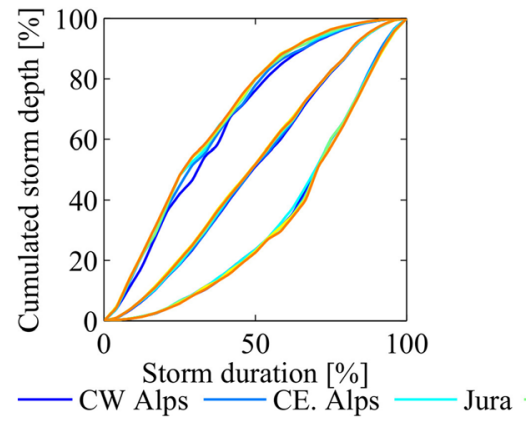

Event duration: $12 \mathrm{~h}$

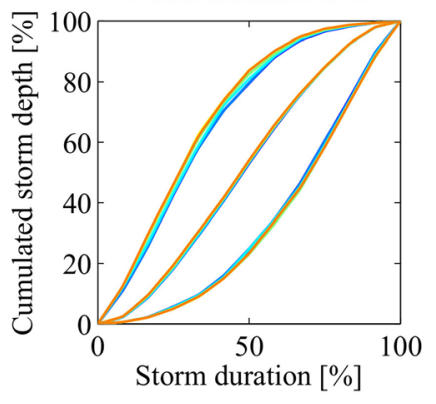

Event duration: $35 \mathrm{~h}$

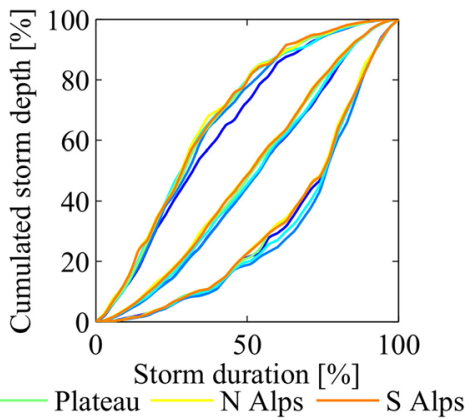

Fig. 5 As Fig. 4 but for winter

winter season (Fig. 5) than for the summer season supports this hypothesis. A detailed physical explanation is, however, beyond the scope of this paper.

The strongest regional RMC variability can be observed between the Central Western Alps and the Northern Alps for an event duration of $35 \mathrm{~h}$ and considering the $50 \%$ quantile curve. For this duration, $23 \%$ of the rainfall volume occurs at a different moment in time for the two regions.

To summarize, regional differences can be observed throughout the seasons but they depend on the considered quantile. These variations seem to be independent of storm duration. The maximum rainfall volume difference between the analyzed quantile RMCs is $23 \%$.

\subsection{Seasonal Variability of Swiss RMCs}

The two regions discussed in detail here are the Southern Alps (high topographic variability, Fig. 6) and the Plateau (no mountains, Fig. 7). The RMCs for the other regions are given in the Supplementary Material, Figures S3 to S6.

The shown quantile RMCs indicate a seasonal dependence for all regions. While the differences between the curves for spring and fall is hardly noticeable, a clear difference is visible between the winter and the summer curves, in particular for the $95 \%$ quantile curves, with a maximum displacement of $25 \%$ of the precipitation volume between summer and winter for the Southern Alps (Fig. 6). The 95\% quantile RMCs show in addition a slight dependence on the storm duration, in particular for the Southern Alps that shows a distinct 95\% RMC shape for the 4 h-events. 
Seasonality in the Mountains (Southern Alps)

Event duration: $4 \mathrm{~h}$

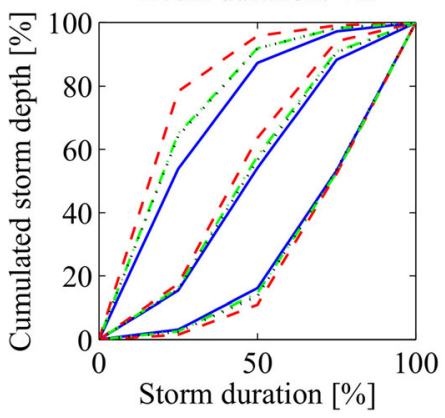

Event duration: $12 \mathrm{~h}$

Event duration: $24 \mathrm{~h}$
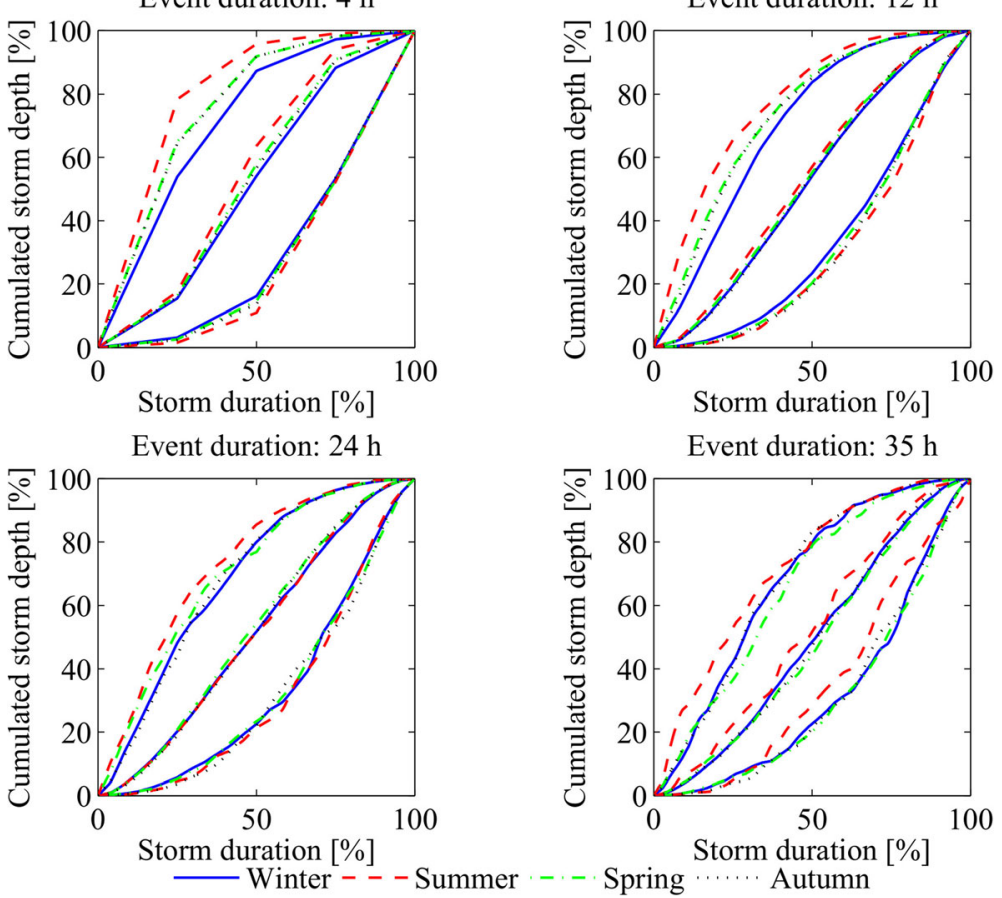

Event duration: $35 \mathrm{~h}$

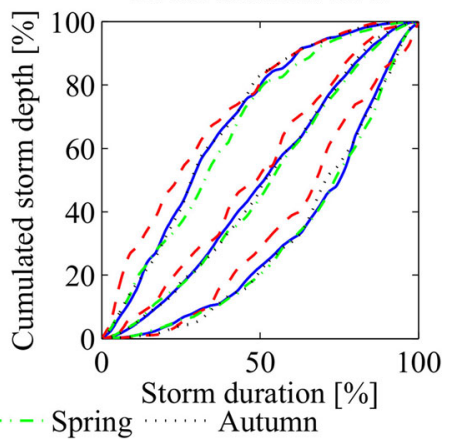

Fig. 6 Seasonal quantile RMCs for the Southern Alps; the panels show the four event durations

The median RMCs are in general less influenced by the season, with a maximum displaced precipitation volume of $20 \%$ (for the $35 \mathrm{~h}$ event). Practically no seasonal variability is apparent for the median curves derived from.

$24 \mathrm{~h}$ storms.

The 5\% quantile curves are only little influenced by the season up to storm durations of $24 \mathrm{~h}$ (the displaced volume portion is smaller than 14\%). The curves derived from $35 \mathrm{~h}$ storms indicate a higher seasonal dependence for the $5 \%$ quantile than for the other quantiles; indeed the difference between the summer and the winter curves corresponds to $25 \%$ of the precipitation volume for the Southern Alps.

In summary, it can be retained that there exists a seasonal dependence throughout the six Swiss regions and that these differences correspond to a maximum of $25 \%$ of the rainfall volume that precipitates at a different moment in time.

\subsection{Dependence on the Event Duration}

The analyzed event durations range from $3 \mathrm{~h}$ to $35 \mathrm{~h}$ with steps of $1 \mathrm{~h}$. The same two regions are used to illustrate the influence of the event duration on the RMCs, i.e. the Southern Alps (Fig. 8) and the Plateau (Fig. 9). For the other regions, see Figures S7 to S10 in the Supplementary Material. A clear dependence on the event duration can be seen. The variability of the RMCs is the smallest for winter and culminates in summer. It is apparent that the $95 \%$ curve is moving towards the median curve with increasing event duration. For the median curve, a difference can only be seen during approximately the 


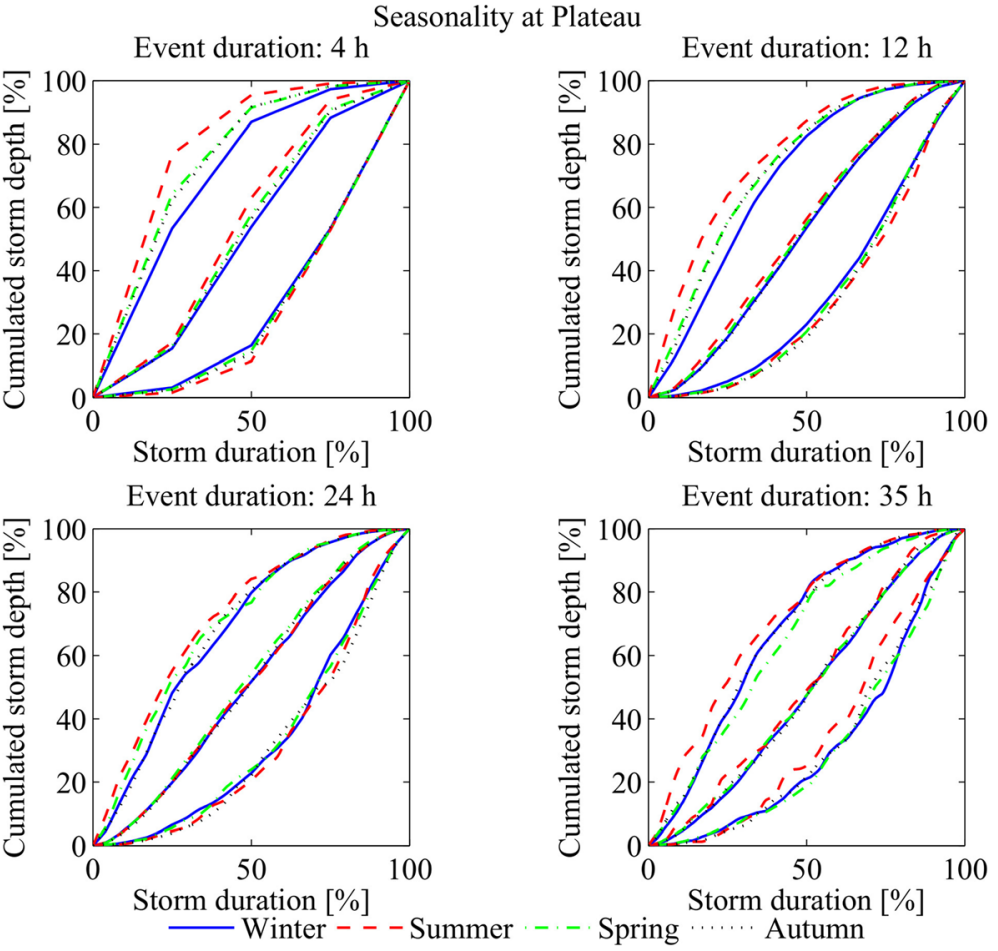

Fig. 7 Seasonal quantile RMCs for the Plateau region; the panels show the four event durations
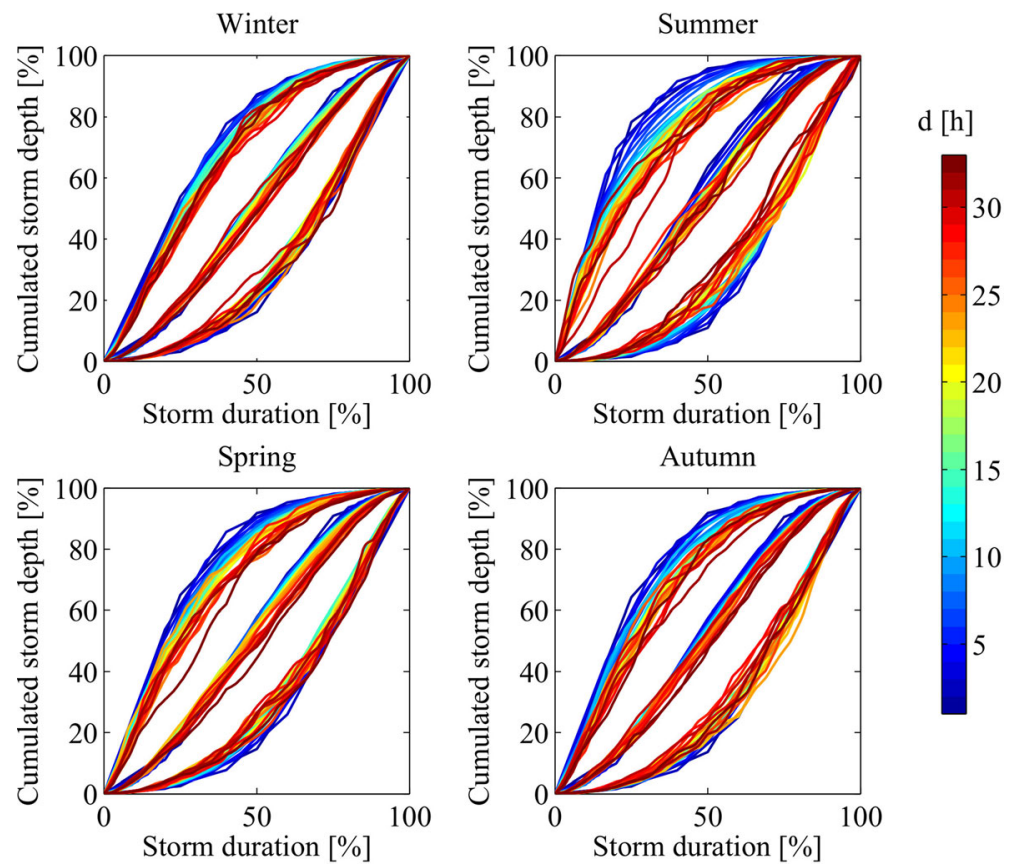

Fig. 8 Duration-dependent RMCs for the Southern Alps; the panels show the four seasons 

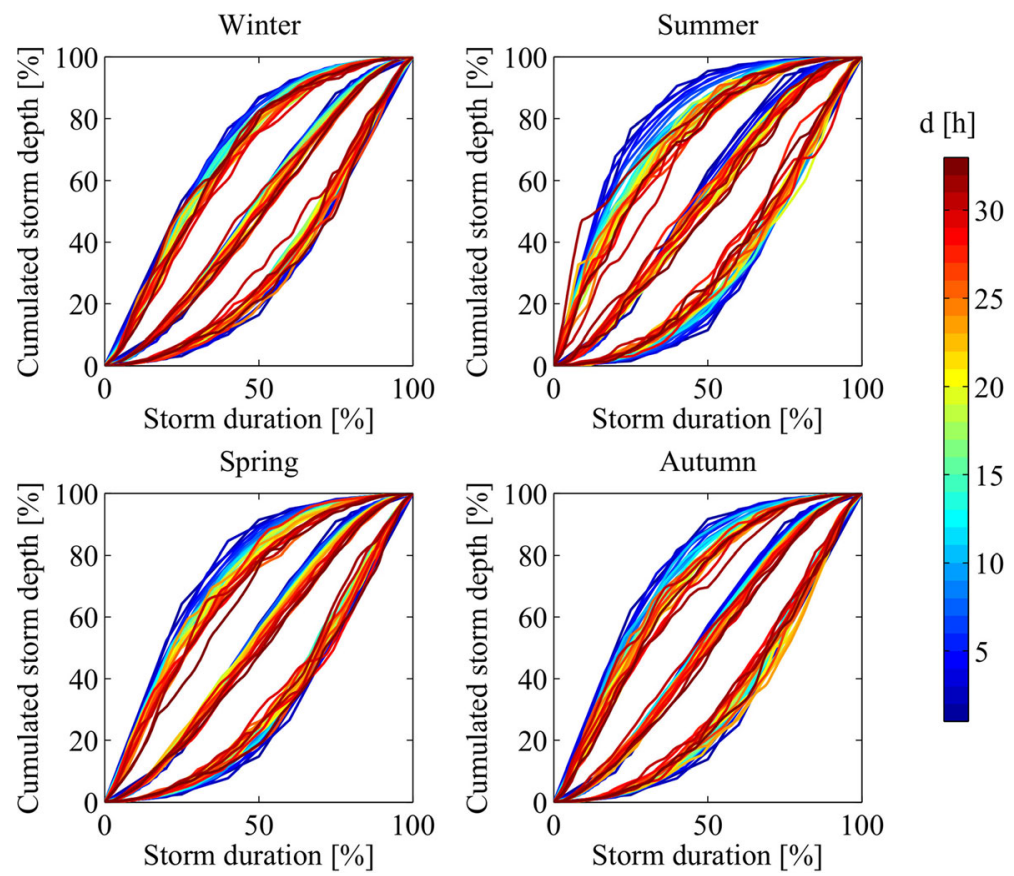

Fig. 9 Seasonal RMCs for the Plateau region; the panels show the four event durations

last $50 \%$ of the storm duration: longer events tend to burst later, especially in summer and autumn.

Concerning the $5 \%$ quantile curves, summer and spring RMCs show that during the first half of the event, a higher volume tends to be released for long storms than for short storms. After approximately $60 \%$ of the event duration, long and short storms behave similarly.

The maximum difference between the duration dependent RMCs is achieved for summer in the Southern Alps for the 95\% quantile curves (i.e. for early bursting curves). Here, the temporally displaced precipitation volume reaches $38 \%$ between the RCM for the $4 \mathrm{~h}$-events and the $33 \mathrm{~h}$-events.

A similar duration dependence as for the Southern Alps and the Plateau is visible for all other regions (Figures S7 to S10 in the Supplementary Material).

\subsection{Regional Assessment of the Reference RMC}

When working with quantile RMCs, the question arises, whether they represent realistic precipitation events or whether they result from a smoothing effect due to the quantile estimation. This question is addressed in detail for the identified reference quantile RMCs (Fig. 3) by comparing them to actual observed RMCs. Figure 10 shows that RMCs derived from single real events can be similar to the reference quantile RMCs. This is shown to be valid for all six analyzed regions. Consequently, the reference quantile RMCs can be considered to represent realistic temporal rainfall distributions. 

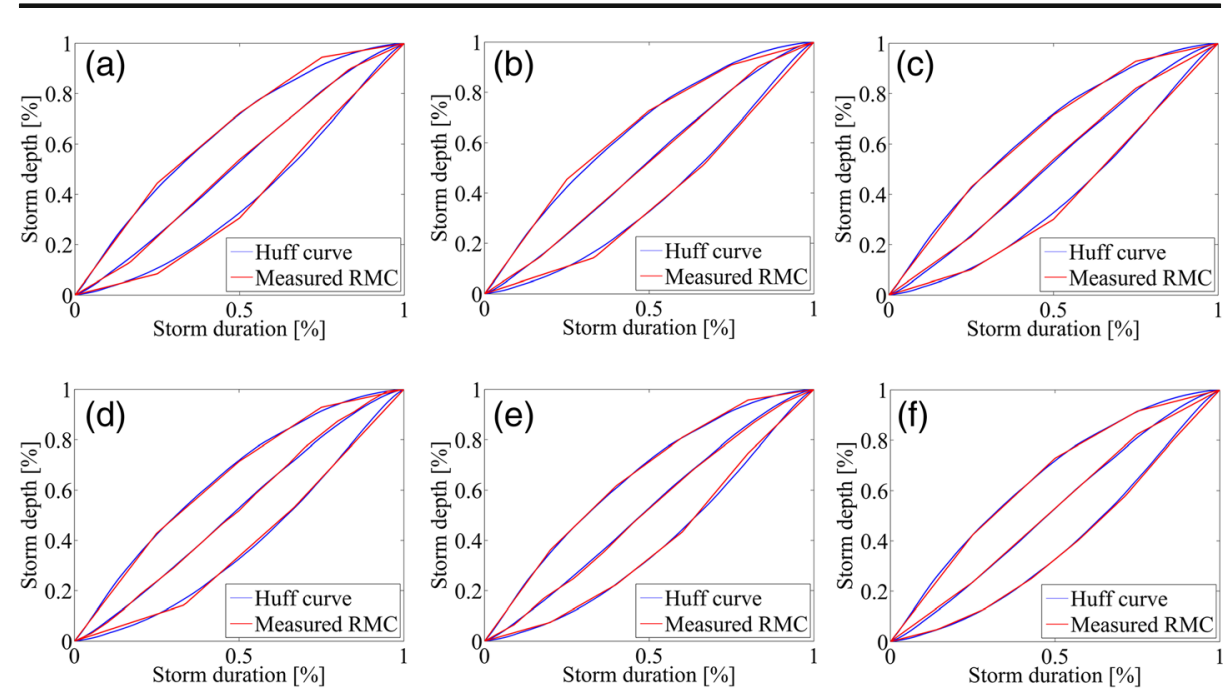

Fig. 10 Comparison between the reference quantile RMCs of Fig. 3 and the most similar observed RMCs for a) Central Eastern Alps, b) Central Western Alps, c) Jura, d) Plateau, e) Northern Alps, f) Southern Alps

\section{Relevance of the Rainfall Mass Curve Variability for Extreme Flood Estimation}

Given that regional RMC variability has been shown here to be smaller than seasonal or duration-dependent variability, only these last two sources of variability are analyzed in detail here.

The variability of the flood hydrographs and the reservoir levels are analyzed for the three quantile RMCs 5\%, 50\% and 95\%. The resulting hydrographs are shown in Fig. 11 and the evolution of the water level in the reservoir in Fig. 12. Both figures show that the influence of the RMC shape is small. For the 5\% quantile RMCs, the ratios between the peak discharges, comparing the reference quantile curves to the seasonal and duration-dependent scenarios, show that the reference RMC returns lower discharge peaks. The ratios show in particular that the reference RMC leads to discharge peak underestimations between 5 and 15.\%. For the median RMCs, the underestimation goes from $3 \%$ to $11 \%$, and from $6 \%$ to $16 \%$ for the $95 \%$ quantile RMCs.
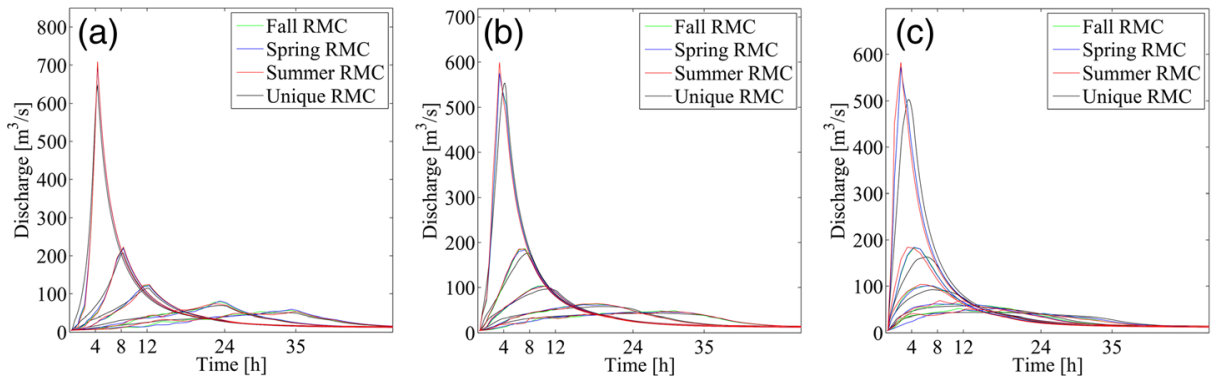

Fig. 11 Mattmark case study: comparison of the generated PMF discharges for seasonal quantile RMCs and for the reference Swiss RMC (labelled unique RMC) for five different PMP durations ( $4 \mathrm{~h}, 8 \mathrm{~h}, 12,24 \mathrm{~h}$ and $35 \mathrm{~h}$ ); a) $5 \%$, b) $50 \%$ and c $95 \%$ 

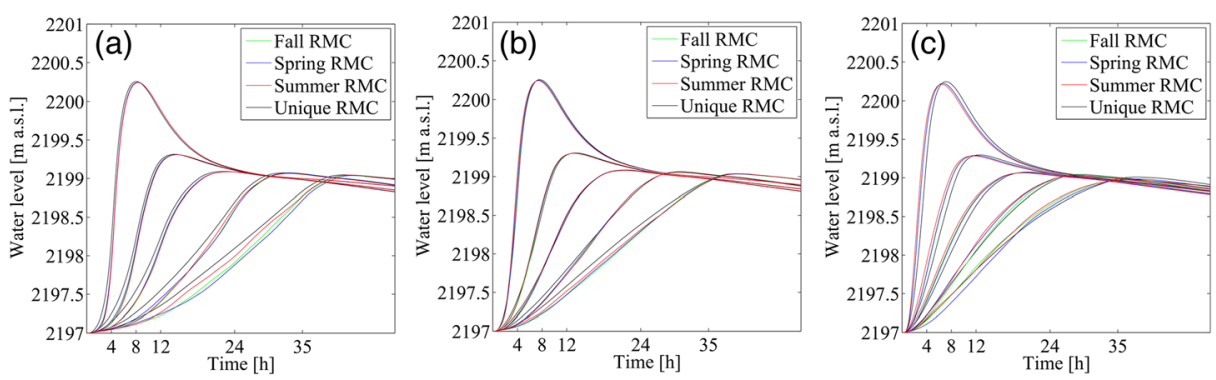

Fig. 12 As Fig. 11 bur for the reservoir level evolution

Interestingly, when estimating these ratios based on the estimated lake level increases (only the net increase is considered for the ratio estimation, the reference level is put at $2197 \mathrm{~m}$ a.s.l.), it can be seen that the reference RMC actually returns higher level estimates than the seasonal and durationdependent RMCs. However, the differences are negligible, the ratios being smaller than $1.8 \%$. Whereas the different quantile RMCs have a non-negligible influence on the discharge peak, their influence on the maximum lake level is hardly recognizable.

Finally, comparing all discharge and reservoir simulations across all event durations, it can be seen that the $5 \%$ quantile RMC (corresponding to early bursting events) yields the highest peak values (for discharge and level) and is thus the most relevant RMC for extreme flood estimation for this particular case study.

\section{Conclusions}

This is the first detailed study of Swiss rainfall mass curves (RMCs) for flood estimation applications. The key of the analysis are the proposed quantile RMCs that are obtained by pooling together the RMCs of many precipitation events observed at single rain gauges.

The present study analyzed in detail the regional and seasonal variability of the 5\%, 50\% and $95 \%$ quantile RMCs and investigated the dependence of their shape on the rainfall event duration. Such dependencies could indeed be found at the level of the region, the season and the precipitation event duration. The RMC shape variability expressed in terms of volumetric differences (i.e. water precipitating at different moments in time) can reach up to $38 \%$ for events of different durations. Regional and seasonal differences were shown to lead to lower RMC variability, with volumetric differences of $23 \%$ and $25 \%$.

The application of the quantile RMCs to extreme flood simulation for a high Alpine case study, however, demonstrated that RMC variability might be sufficiently small to justify the use of a unique set of reference Swiss RMCs instead of regional, seasonal and durationdependent curves. The variation of the simulated peak discharges obtained with seasonal RMCs differed in fact only a few percents (between $3 \%$ and 16\%) from those obtained with the reference Swiss RMCs. The use of these reference quantile RMCs for entire Switzerland is particular promising since they have been shown in this paper to correspond closely to the temporal structure of actual observed precipitation events.

The analysis of temporal distribution of precipitation for design purposes might be refined in the future by explicitly accounting for different precipitation event types, such as orographic or convective events. Recent progress in the fields of extreme precipitation simulation for 
future climates in Europe (Rajczak and Schär 2017) and of PMP estimation under evolving climates (Chen et al. 2017) also opens new perspectives for the analysis of RMCs under future climates.

Acknowledgements This work was funded by the Swiss Federal Office of Energy (SFOE). The work of B. Schaefli was supported by the the Swiss Competence Center on Energy Research-Supply of Energy, and by the Swiss National Science Foundation, grant number PP00P2_157611. Precipitation data has been provided by MeteoSwiss. The authors also thank the engineering company e-dric.ch for their hydrological modeling software and the engineering company Hertig \& Lador SA for the PMP data (elaborated for the SFOE). The Swiss PMP values should become freely available in the near future. The data corresponding to the identified Swiss-wide reference quantile RMCs is available in the Supplementary Material.

\section{Compliance with Ethical Standards}

Conflict of Interest The authors declare that they have no conflict of interest.

\section{References}

Alfieri L, Laio F, Claps P (2008) A simulation experiment for optimal design hyetograph selection. Hydrol Process 22(6):813-820

Azli M, Rao AR (2010) Development of Huff curves for Peninsular Malaysia. J Hydrol 388(1-2):77-84

Back AJ (2011) Time distribution of heavy rainfall events in Urussanga, Santa Catarina State, Brazil. Acta Sci Agron 33(4):583-588

Bérod D, Devred D, Laglaine V, Chaix O, Altinakar M, Delley P (1992) Calcul des crues extrêmes par des méthodes déterministes du type pluie maximale probable (PMP) / crue maximual probable (PMF), Application au cas de la Suisse. Institut d'aménagement des terres et des eaux, Ecole Polytechnique Fédérale de Lausanne (EPFL); Bonnard et Gardel, Ingénieurs Conseils SA (BG); SA Ufficio d'ingegneria Maggia, Locarno (IM), Lausanne

Bonta J (2004) Development and utility of Huff curves for disaggregating precipitation amounts. Appl Eng Agric 20(5):641

Bonta J, Shahalam A (2003) Cumulative storm rainfall distributions: comparison of Huff curves. J Hydrol N Z 42(1):65-74

Caballero W, Rahman A (2013) Variability in Rainfall Temporal Patterns: A Case Study for New South Wales, Australia. J Hydro Environ Res 1(1):41-48

Chen X, Hossain F, Leung LR (2017) Probable maximum precipitation in the u.s. pacific northwest in a changing climate. Water Resour Res. https://doi.org/10.1002/2017WR021094

Dolsak D, Bezak N, Sraj M (2016) Temporal characteristics of rainfall events under three climate types in slovenia. J Hydrol 541:1395-1405. https://doi.org/10.1016/j.jhydrol.2016.08.047

Ghassabi Z, Kamali GA, Meshkatee AH, Hajam S, Javaheri N (2016) Time distribution of heavy rainfall events in south west of Iran. J Atmos Sol Terr Phys 145:53-60

Golian S, Saghafian B, Maknoon R (2010) Derivation of probabilistic thresholds of spatially distributed rainfall for flood forecasting. Water Resour Manag 24(13):3547-3559

Guo JC, Hargadin K (2009) Conservative design rainfall distribution. J Hydrol Eng 14(5):528-530

Hertig JA, Fallot JM (2009) Validation et utilisation des cartes de PMP pour l'obtention de la PMF. Projet CRUEX: Directives Crues de l'OFEN. unpublished report

Hertig JA, Audouard A, Plancherel A (2005) Cartes des précipitations extrêmes pour la Suisse (PMP 2005). Rapport EFLUM-EPFL

Huff FA (1967) Time distribution of rainfall in heavy storms. Water Resour Res 3(4):1007-1019

Jordan F, Brauchli T, Garcia Hernandez J, Bieri M, Boillat JL (2012) RS 2012, Rainfall-Runoff Modelling. User guide. unpublished manual, e-dric.ch, Lausanne

Keifer C, Chu H (1957) Synthetic storm pattern for drainage design. ASCE Journal of the Hydraulics Division 83(HY4): $1-25$

Kimoto A, Canfield HE, Stewart D (2011) Comparison of Synthetic Design Storms with Observed Storms in Southern Arizona. J Hydrol Eng 16(11):935-941

National Environment Research Council (1975) Flood Studies Report, Meteorological studies, vol 2. Whitefriars Press Ltd., London 
Natural Resources Conservation Service (1986) Technical Release 55 (TR-55). Urban hydrology for small watersheds, Natural Resources Conservation Service, Engineering Division, Washington, D.C.

Pan CL, Wang XW, Liu L, Huang HB, Wang DS (2017) Improvement to the huff curve for design storms and urban flooding simulations in guangzhou, china. Water 9(6). https://doi.org/10.3390/w9060411

Pedrozzi G (2004) Triggering of landslides in canton ticino (switzerland) and prediction by the rainfall intensity and duration method. Bull Eng Geol Environ 63(4):281-291. https://doi.org/10.1007/s10064-004-0240-y

Prodanovic P, Simonovic SP (2004) Generation of Synthetic Design Storms for the Upper Thames River Basin. CFCAS Project: Assessment of Water Resources Risk and Vulnerability to Changing Climatic Conditions. Tech. rep. The University of Western Ontario, Department of Civil and Environmental Engineering

Rajczak J, Schär C (2017) Projections of future precipitation extremes over europe: A multimodel assessment of climate simulations. J Geophys Res-Atmos 122(20):10,773-10,800. https://doi.org/10.1002/2017JD027176

Schaefli B, Zehe E (2009) Hydrological model performance and parameter estimation in the wavelet-domain. Hydrol Earth Syst Sci 13(10):1921-1936

Schaefli B, Hingray B, Niggli M, Musy A (2005) A conceptual glaciohydrological model for high mountainous catchments. Hydrol Earth Syst Sci 9(1/2):95-109

Shaw L, Hamilton PA, Kent CE (1984) Temporal Distribution of Rainfall in Virginia. Tech. rep., Virginia Highway \& Transportation Research Council

Swiss Federal Office for the Environment (2001) Die biogeographischen Regionen der Schweiz. UmweltMaterialien UM, Federal Office for the Environment FOEN, Bern

Tsihrintzis VA, Sidan CB (1998) Modeling urban stormwater runoff processes using the santa barbara method. Water Resour Manag 12(2):139-166

Veneziano D, Villani P (1999) Best linear unbiased design hyetograph. Water Resour Res 35(9):2725-2738

Vernieuwe H, Vandenberghe S, De Baets B, Verhoest N (2015) A continuous rainfall model based on vine copulas. Hydrol Earth Syst Sci 19(6):2685-2699

Watt E, Marsalek J (2013) Critical review of the evolution of the design storm event concept. Can J Civ Eng 40(2):105-113

World Meteorological Organisation (2009) Manual on Estimation of Probable Maximum Precipitation (PMP), vol WMO-No.1045. World Meteorological Organization, Geneva

Zeimetz F (2017) Development of a methodology for extreme flood estimations in alpine catchments for the verification of dam safety. phd thesis, ecole polytechnique federale de lausanne, available at library.epfl. ch/theses (last Accessed 01. 12. 2017). PhD thesis

Zeimetz F, Schaefli B, Artigue G, García Hernández J, Schleiss AJ (2017) Relevance of the correlation between precipitation and the $0^{\circ} \mathrm{c}$ isothermal altitude for extreme flood estimation. J Hydrol 551:177-187. https://oi. org/10.1016/j.jhydrol.2017.05.022

Zeimetz F, Schaefli B, Artigue G, García Hernández J, Schleiss A (in press) A new approach to identify critical initial conditions for extreme flood simulations based on deterministic and stochastic simulation. Journal of Hydrologic Engineering 